\title{
Development of Electrospun Films from Wastewater Treatment Plant Sludge
}

\author{
Gregor Lavrič ${ }^{1}$, Aleksandra Miletić ${ }^{2} \oplus$, Branka Pilić ${ }^{2}$, Daša Medvešček ${ }^{1}$, Saša Nastran ${ }^{3}$ \\ and Urška Vrabič-Brodnjak ${ }^{4, *(1)}$
}

1 Pulp and Paper Institute, Bogišićeva ulica 8, 1000 Ljubljana, Slovenia; gregor.lavric@icp-lj.si (G.L.); dasa.medvescek@icp-lj.si (D.M.)

2 Faculty of Technology, University of Novi Sad, Bulevar cara Lazara 1, 21000 Novi Sad, Serbia; alexm@uns.ac.rs (A.M.); brapi@uns.ac.rs (B.P.)

3 JP Voka Snaga d.o.o., Vodovodna cesta 90, 1000 Ljubljana, Slovenia; sasa.nastran@vokasnaga.si

4 Department of Textiles, Graphic Arts and Design, Faculty of Natural Sciences and Engineering, University of Ljubljana, Snežniška 5, 1000 Ljubljana, Slovenia

* Correspondence: urska.vrabic@ntf.uni-lj.si

check for updates

Citation: Lavrič, G.; Miletić, A.; Pilić,

B.; Medvešček, D.; Nastran, S.;

Vrabič-Brodnjak, U. Development of Electrospun Films from Wastewater Treatment Plant Sludge. Coatings 2021, 11, 733. https://doi.org/ 10.3390/coatings11060733

Academic Editor: Sandra Dirè

Received: 21 May 2021

Accepted: 17 June 2021

Published: 18 June 2021

Publisher's Note: MDPI stays neutral with regard to jurisdictional claims in published maps and institutional affiliations.

Copyright: (c) 2021 by the authors. Licensee MDPI, Basel, Switzerland. This article is an open access article distributed under the terms and conditions of the Creative Commons Attribution (CC BY) license (https:// creativecommons.org/licenses/by/ $4.0 /)$

\begin{abstract}
Electrospinning is a versatile method for producing continuous polymer nanofibers, including from wastewater treatment plant sludge (WTPS). In this context, purified WTPS was successfully used to produce electrospun fibers. The main objective of our research was to produce new, local, circular, renewable and environmentally friendly packaging material. The aim of the research was to purify and treat WTPS to make it suitable for the electrospinning process, thus producing a new material and chemically characterizing it in the first step. One of the major advantages of our process was that the electrospinning process could be carried out with water and ethylenediaminetetraacetic acid. The optimal viscosity was determined to be 20,000 $\mathrm{mPas}$ in order to produce sufficient nanofibers. Analyses such as Fourier-Transform Infrared Spectroscopy (FTIR) and ${ }^{1} \mathrm{H}-\mathrm{NMR}$ (proton nuclear magnetic resonance) were used to determine the substances of unpurified and purified WTPS. The tensile properties, contact angle, surface properties and differential scanning calorimetry of the final material were determined and used. The ${ }^{1} \mathrm{H}-\mathrm{NMR}$ analysis confirmed the presence of a small quantity of polyhydroxyalkanoates in the samples. Based on the properties, the final material was brittle and less stretchable compared to electrospun packaging films available in the market.
\end{abstract}

Keywords: wastewater treatment; electrospinning; differential scanning calorimetry; tensile properties; proton nuclear magnetic resonance spectroscopy; packaging

\section{Introduction}

The extensive consumption of natural resources in recent years is reflected in the increasing consumption of packaging [1], which consequently causes the increase of the amount of plastic waste. According to the World Economic Forum, there will be more plastic than fish in the oceans by 2050 if human habits persist [2]. From a different perspective, the current global health crisis has highlighted the importance of using local and easily accessible raw materials that do not have to travel long distances to reach the consumer. These facts indicate that all future packaging materials should be renewable, environmentally friendly and, if possible, made from alternative raw materials (e.g., industrial waste) [3,4]. In general, waste is described as a product or by-product substance derived from industrial or agricultural processes or other activities with end-use purposes [5]. Waste can be a direct result of processing technology or the product of secondary treatment of waste streams, for example, wastewater, which produces several types of wastewater treatment plant sludge.

Depending on the treatment stage, primary, secondary, tertiary and chemical sludges are produced. Primary sludge is formed during primary treatment (screening, grate removal, flotation, precipitation and sedimentation) when heavy solids, grease and oils are 
separated from raw wastewater [6,7]. Usually, the primary sludge contains $2-9 \%$ solids. The remaining $90 \%$ (sometimes $99.5 \%$ ) is water. Secondary sludge (waste activated sludge) is formed during biological treatment when the biodegradable organic content of wastewater is degraded by microorganisms. The total concentration of solids ranges from $0.8 \%$ to $3.3 \%$, depending on the type of biological treatment process, with the remainder being water [7]. The organic fraction of waste activated sludge contains $50-55 \%$ carbon, $25-30 \%$ oxygen, $10-15 \%$ nitrogen, $6-10 \%$ hydrogen, $1-3 \%$ phosphorus and $0.5-1.5 \%$ sulfur [8]. Tertiary sludge is produced in advanced wastewater treatment stages when nutrients (nitrogen and phosphorus) need to be removed [6]. Usually, nutrient removal is carried out simultaneously with organic matter removal. Chemical sludge is produced by chemical processes carried out at the municipal wastewater treatment plant, such as chemically assisted primary sedimentation. In this process, an appropriate coagulant is added to the primary clarifier to reduce the organic load for further biological treatment. The qualitative and quantitative properties of the sludge depend on the reagent used and the dosage. Typical reagents are hydrated lime, ferric chloride, aluminum sulfate and chitosan. Chemical sludge may contain non-negligible quantities of metals, due in part to the inorganic coagulants used. Chemical sludge can also be produced by coagulation-flocculation of the supernatant thickener and by backwashing after sedimentation/chemical-physical treatment [9].

Due to legislation restricting the use of landfills and land as sludge disposal methods, many researchers have attempted to reuse and recycle sludge in the most sustainable possible way [9-25]. Taking into account that the organic components of sludge present a rich source vein in terms of energy and nutrients waiting to be tapped, various studies show that, in the context of the circular economy, an important advantage of energy and fuels derived from waste is that they can replace other energy resources and limit the associated $\mathrm{CO}_{2}$ emissions. From a scientific point of view, the challenge of sewage sludge is one of the most studied in the last 30 years. The concepts of material and energy recovery, which are milestones of today's circular economy, have already been addressed by several working groups [19-22]. Most of the studies on the material utilization of wastewater sludge are based on the extraction of polyhydroxyalkanoates [9].

Over the years, it has been shown that wastes generated mainly from processes in the agricultural, food, textile and paper industries have a high end-use potential [10]. A good example of high-end potential from the agri-food sector is waste from coffee production, as described by Figueroa et al. and Malara et al. [11,12]. As a waste solution, an anthocyaninbased milk freshness indicator or sensor that could be used as an indicator of actual milk quality was shown by Weston et al. [13]. Researchers have also presented available technologies and materials for exploited cooking oil recycling, which has a significant impact on household waste solutions [14-16]. In recent years, substantial progress has been made in waste processing in the textile and paper industries [17-22].

In the past, studies on the utilization of wastewater treatment plant sludge (WTPS) for various purposes have been published [9,23-25]. Most of them are based on the extraction of polyhydroxyalkanoates (PHAs) from WTPS. PHAs are a class of bio-based and biodegradable polymers produced by bacterial fermentation of complex organic substrates [25]. They belong to the class of polyesters and can be thermoplasts or elastomers, and depending on the structure, they have similar properties to the conventional plastics, which makes PHAs suitable candidates for their substitution [25]. Despite the extensive literature review, no report of the direct use of WTPS for material preparation by electrospinning has been published so far. The materials produced by electrospinning technology are intended for a variety of applications in many fields such as medicine, pharmaceuticals, biotechnology, sustainable engineering materials and even packaging [26-28]. The advantage of the above technology lies in the production of nanofibers and their small diameter, large specific surface area and high porosity. Meanwhile, the rapid development of nanotechnology has enabled new applications for electrospun materials. In general, electrospinning technology is a new strategy for environmentally friendly nanomaterials 
with special properties and a promising solution for wastewater sludge as well. Accordingly, at least a partial presence of various biopolymers in a local WTPS was expected. With the main objective of producing a new, local, circular, renewable and environmentally friendly packaging material, the sludge was chemically characterized at the beginning of the research. The main advantage of our process is that the electrospinning solution was prepared using water and ethylenediaminetetraacetic acid (EDTA). However, the aim of the research was to clean and treat the wastewater treatment plant sludge in such a way that it is suitable for the electrospinning process, thus creating a new material.

\section{Materials and Methods}

\subsection{Materials}

Preparation of wastewater treatment plant sludge solution (WTPS): The WTPS was obtained from the main wastewater treatment plant of Ljubljana. The purification procedure was carried out according to a slightly modified method described by Fang and Jia in 1996 [29]. The purification was based on dissolution of WTPS in a 2\% EDTA solution in water and centrifugation. Fifty grams of the absolute dry mass of WTPS was firstly cut down into pieces with a size of $\sim 1 \mathrm{~cm} \times 1 \mathrm{~cm}$. The pieces were then dissolved in a $300 \mathrm{~mL}$ EDTA solution and stirred in a $500 \mathrm{~mL}$ beaker $(500 \mathrm{rpm}, 24 \mathrm{~h})$. Centrifugation $(16,800 \times g$, $30 \mathrm{~min}$ ) and separation of the usable supernatant were the final steps of the process. A series of solutions with different viscosities $(20,000,5000$, and $2000 \mathrm{mPa})$ were prepared by water evaporation from the initial solution of WTPS by heating in a water bath $\left(85^{\circ} \mathrm{C}\right.$, $\sim 240 \mathrm{~min}$ ) while stirring at $250 \mathrm{rpm}$ in order to optimize the process of electrospinning, since it was impossible to obtain continuous nanofibers from the initial solution.

\subsection{Methods}

\subsubsection{Electrospinning Process}

The electrospinning process was carried out using a Fluidnatek LE -10 electrospinning machine (Bioinicia, Valencia, Spain). Main process parameters: flow rate $(\mu \mathrm{L} / \mathrm{h})$, needle-to-collector distance $(\mathrm{cm})$ and voltage $(\mathrm{kV})$ were optimized to obtain a satisfactory nanofiber morphology, without visible defects, beads or drops within the fiber structure. The optimal voltage was $19 \mathrm{kV}$, flow rate was $200 \mu \mathrm{L} / \mathrm{h}$ and needle-to-collector distance was $15 \mathrm{~cm}$.

\subsubsection{Material Characterization}

Viscosity Determination

The rheology (viscosity) of the solution was determined using a Viscotech 3000 viscometer (Viscotech Hispania, SL, El Vendrell-España, Spain) according to the Brookfield method. A $20 \mathrm{~mL}$ sample was analyzed at room temperature $\left(22 \pm 0.5^{\circ} \mathrm{C}\right)$ in an appropriate container providing convenient spindle-to-wall distance.

Fourier-Transform Infrared Spectroscopy (FTIR)

Fourier-transform infrared spectra analysis of WTPS was performed using a Spectrum One ATR-FTIR spectrometer (Perkin Elmer, Waltham, MA, USA). Scans were performed between the infrared regions at $4000-400 \mathrm{~cm}^{-1}$, with an average of 64 scans.

\section{Proton Nuclear Magnetic Resonance Spectroscopy $\left({ }^{1} \mathrm{H}\right.$ NMR $)$}

Proton nuclear magnetic resonance spectroscopy of WTPS was performed using an Agilent Technologies DD2 spectrometer (Agilent Technologies, Santa Clara, CA, USA). The WTPS samples were dissolved in $\mathrm{D}_{2} \mathrm{O}$ with trifluoroacetic acid (TFA) and deuterated chloroform $\left(\mathrm{CDCl}_{3}\right)$ for the purpose of analysis.

Differential Scanning Calorimetry (DSC)

Differential scanning calorimetry of purified WTPS was conducted with a differential scanning calorimeter (TA Instruments Q20, New Castle, DE, USA) within the range of 
-60 to $150{ }^{\circ} \mathrm{C}$. A small amount of sample $(2-5 \mathrm{mg})$ was placed into a DSC pan and analyzed with a heat rate of $10^{\circ} \mathrm{C} / \mathrm{min}$.

\section{Tensile Properties}

Tensile properties were determined using Zwick Roell Z010 (Zwick Roell, Ulm, Germany) tensile testing machine equipped with a $20 \mathrm{~N}$ measuring cell (Class 0.5 , ISO 7500-1). The testing speed was set to $1 \mathrm{~mm} / \mathrm{min}$. Film strips of $1.5 \mathrm{~cm}$ in width and $10 \mathrm{~cm}$ in length were used. During the sample stretching, several load and elongation data per second were recorded until the breaking of a sample occurred.

\section{Contact Angle}

The wettability and water absorption of material were determined by measuring the contact angle of a $4 \mu \mathrm{L}$ water drop using a Fibrodat 1100 (Fibro System AB, Molenbaan, The Netherlands) dynamic contact angle tester. The change in the contact angle in the first $30 \mathrm{~s}$ was measured and evaluated.

\section{Surface Characterization with a Scanning Electron Microscope (SEM)}

The surfaces/structures of electrospun materials were examined with electron scanning microscopy to acquire information about fiber arrangement and the material network in general. The micrographs were taken with a scanning electron microscope JSM-6060 LV (Jeol Ltd., Akishima, Japan). The instrument was operated at $10 \mathrm{kV}$ at $1500 \times$ magnification.

\section{Results and Discussion}

In the first part of this study, WTPS obtained from a local wastewater treatment plant was chemically characterized then purified and prepared for the electrospinning process. This process produced a new thin material that could be used for packaging applications. In the final part of the study, the newly obtained material was characterized in terms of tensile strength and wettability.

\subsection{FTIR and ${ }^{1} H$ NMR Analysis of Wastewater Treatment Plant Sludge}

In order to determine the presence of sodium polyacrylate in purified WTPS, FTIR spectra of purified WTPS were analyzed and compared to the sodium polyacrylate spectra (Figure 1).

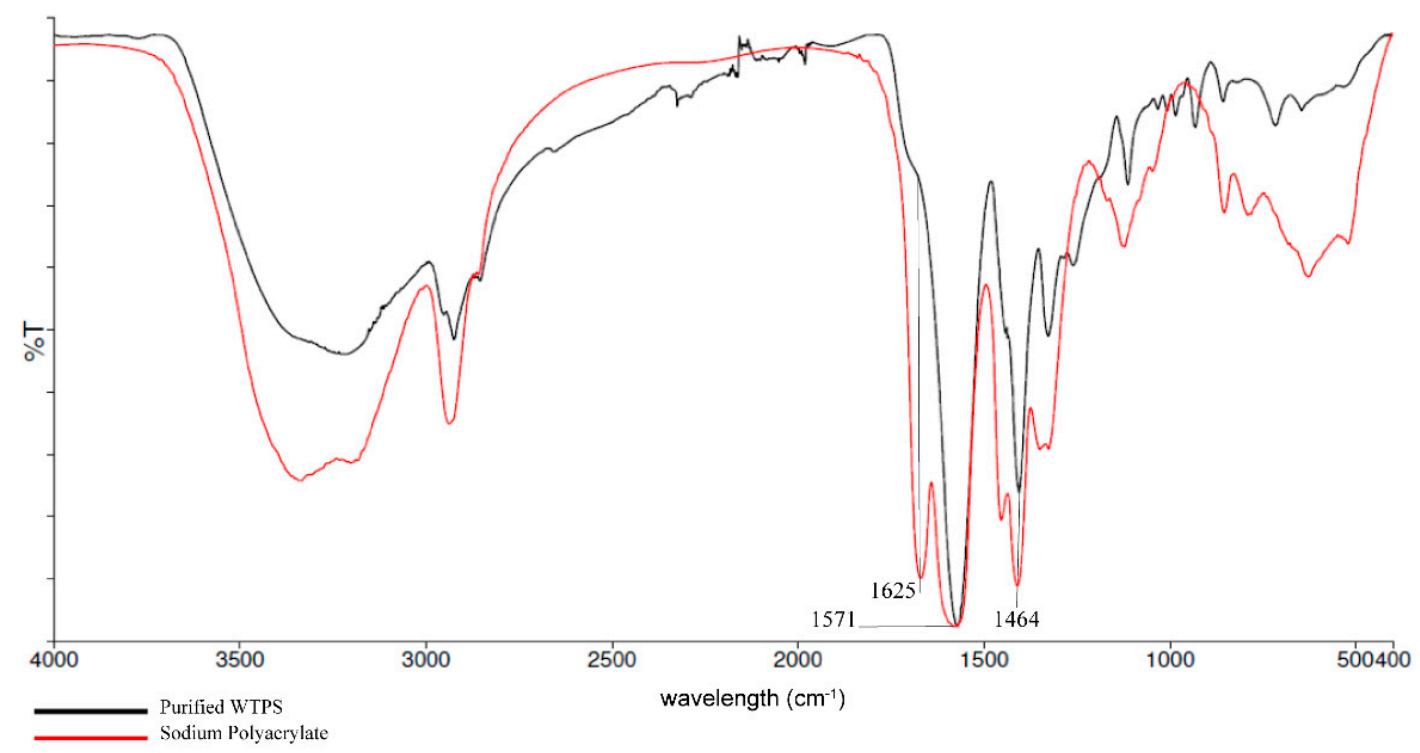

Figure 1. Fourier-transform infrared (FTIR) transmission spectra $(\% \mathrm{~T})$ at the wavelength $\left(\mathrm{cm}^{-1}\right)$ of purified WTPS and sodium polyacrylate. 
As shown, three peaks were observed in the pure sodium polyacrylate at 1464 , 1571 and $1625 \mathrm{~cm}^{-1}$. The peaks at 1464 and $1625 \mathrm{~cm}^{-1}$ are related to the bending of - $\mathrm{CH} 2$ - and the $\mathrm{C}=\mathrm{O}$ stretching mode in the carboxylic acid group of sodium polyacrylate $[30,31]$. From the spectra, it is evident that purified WTPS and sodium polyacrylate share common peaks at 1464,1571 , and $1625 \mathrm{~cm}^{-1}$ corresponding to the bands of sodium polyacrylate. As previously reported in the literature, the strong peak at $1571 \mathrm{~cm}^{-1}$ remains in the FITR spectra of WTPS, which is also masked by the carboxylate ions of WTPS and sodium polyacrylate [31]. At the same time, in the FTIR spectra of sodium polyacrylate and purified WTPS, the peaks in the range of 1625 and $1800 \mathrm{~cm}^{-1}$ are assigned to the carbonyl groups [30-32]. In the purified WTPS sample, the addition of sodium polyacrylate was detected as expected.

To further analyze the unpurified and purified WTPS, a comparison of the spectra was performed (Figure 2). As can be seen from the spectra, in unpurified WTPS, the peak at $1554 \mathrm{~cm}^{-1}$ is shifted to 1571 in purified WTPS. These two peaks correspond to the carboxylate ions [31]. In purified WTPS, more distinct peaks were observed at 2911, 1362, 1181 , and $915 \mathrm{~cm}^{-1}$ wavelengths.

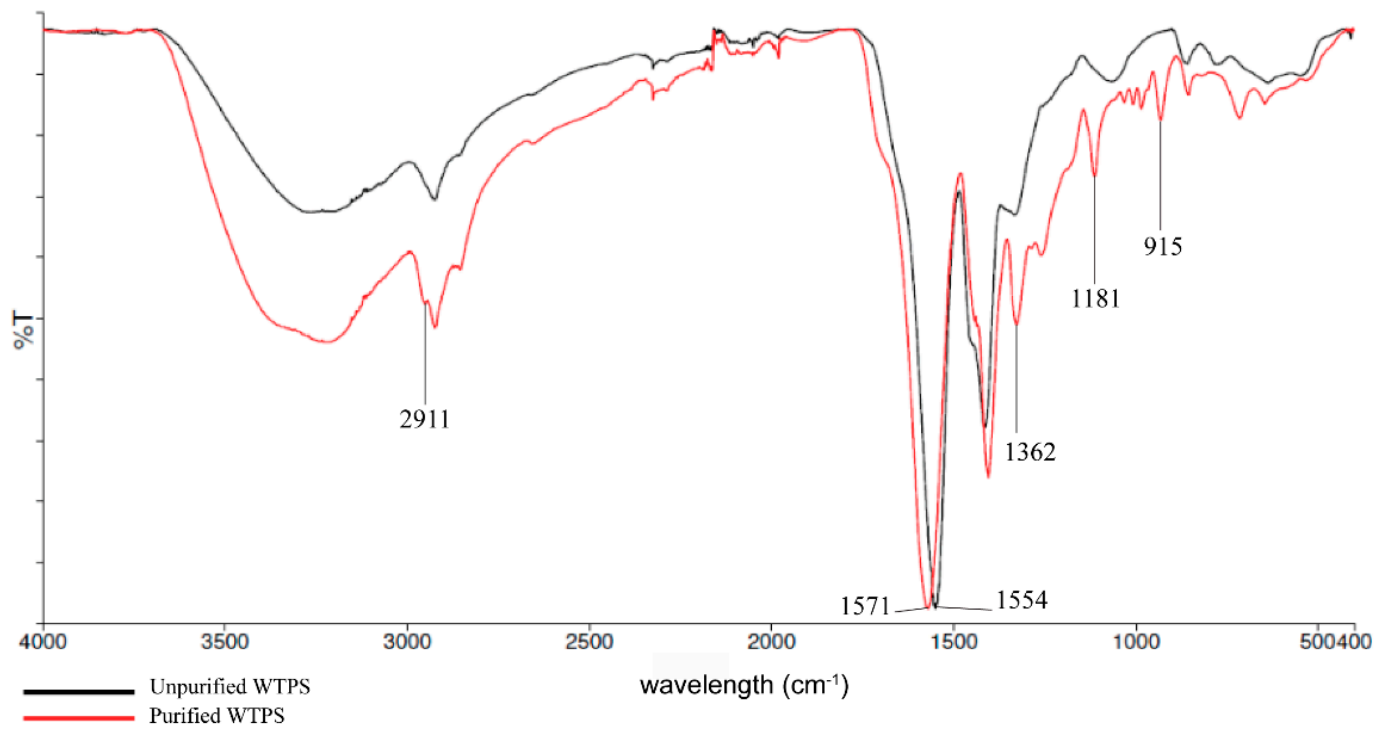

Figure 2. Fourier-transform infrared (FTIR) transmission spectra $(\% \mathrm{~T})$ at the wavelength $\left(\mathrm{cm}^{-1}\right)$ of unpurified and purified WTPS.

Figure 3 illustrates the ${ }^{1} \mathrm{H}-\mathrm{NMR}$ of purified WTPS and sodium polyacrylate. Sodium polyacrylate was used for the purposes of WTPS analysis. Therefore, the presence of this component was also detected in the purified WTPS sample. The characteristic solid peaks on the purified WTPS appeared between 1.6 and $2.6 \mathrm{ppm}$, which are also typical for sodium polyacrylate. A signal at $1.6 \mathrm{ppm}$ belongs to the hydrogen of methylene. The spectra also show the resonance signal $\mathrm{CH}_{2} \mathrm{O}-\mathrm{COOH}$ bond at $2.580 \mathrm{ppm}$. As described in the literature on wastewater analysis, peaks between 3.3 and $4.6 \mathrm{ppm}$ could correspond to glycine (3.5 ppm), glycerol (3.6 ppm), serine (3.7 ppm), 2-aminopropanol (3.9 ppm) and 3-hidroxibutyric acid (4.2 ppm) [33]. For the purified WTPS, the strong peaks were detected at $3.7 \mathrm{ppm}$ corresponding to serine and $4.2 \mathrm{ppm}$ corresponding to 3-hidroxibutyric acid.

Figure 4 presents ${ }^{1} \mathrm{H}-\mathrm{NMR}$ spectra of unpurified WTPS and purified WTPS. The strong peak at $1.53 \mathrm{ppm}$ corresponds to water in chloroform. The peaks of unpurified WTPS are stronger, indicating the addition of carboxylic acid in the sample compared to purified WTPS. At the same time, the minor addition of PHA was observed in both samples, as shown in Figure 4. PHA polymers contain hydrogen and carbon; therefore, typical peaks such as $\mathrm{CH}_{2}$ at $1.35 \mathrm{ppm}$ and $\mathrm{CH}_{3}$ at $0.85 \mathrm{ppm}$ were detected [34]. Typical peaks for PHA also include $\mathrm{CH}$ at $5.2 \mathrm{ppm}$ and $\mathrm{CH}_{2}$ at $2.55 \mathrm{ppm}$, which were not detected 
in our samples [35]. The peak $\mathrm{CH}_{2}$ at $1.6 \mathrm{ppm}$ was present but was also masked by the water and chloroform.

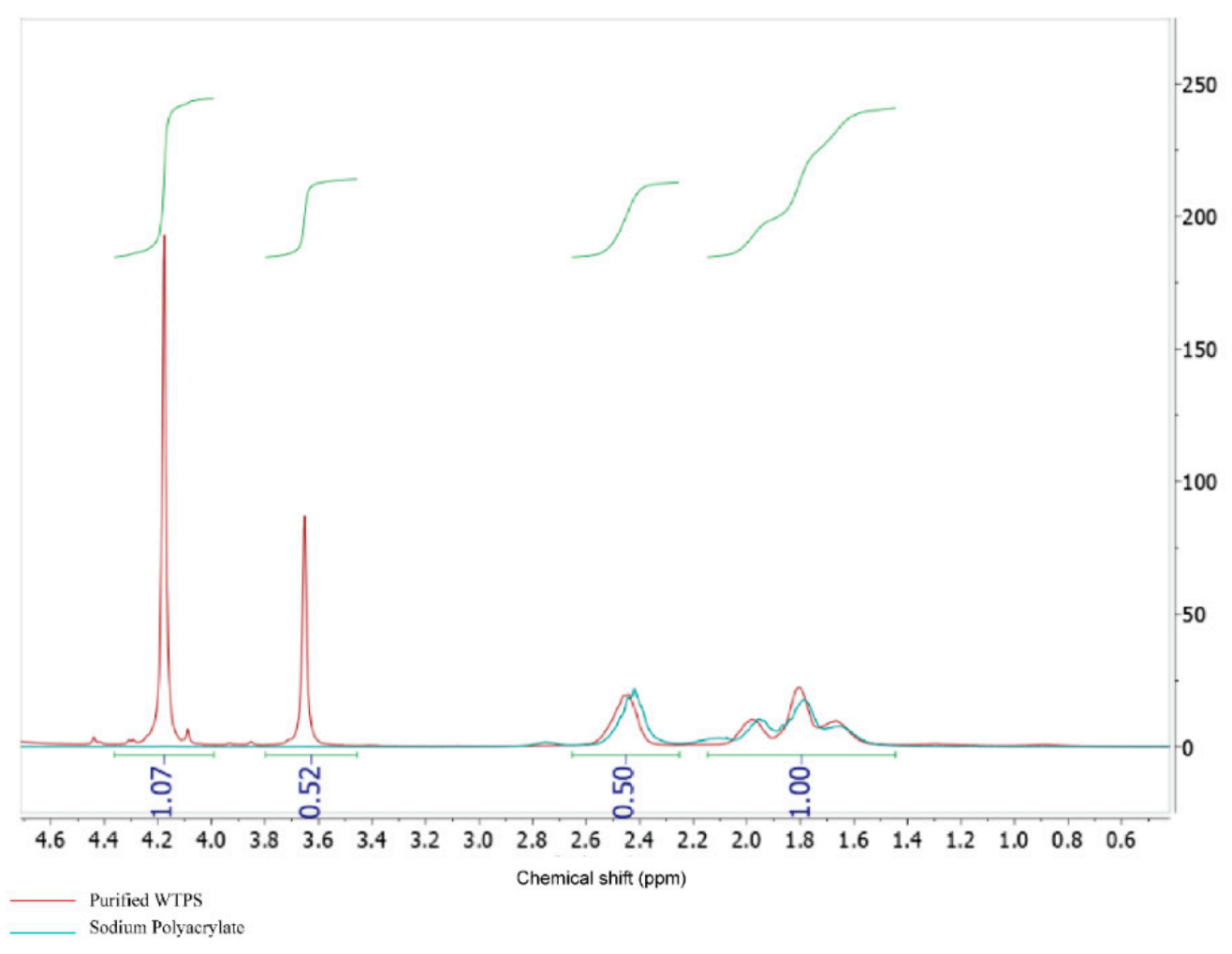

Figure 3. ${ }^{1} \mathrm{H}-\mathrm{NMR}$ spectra of purified WTPS and sodium polyacrylate.

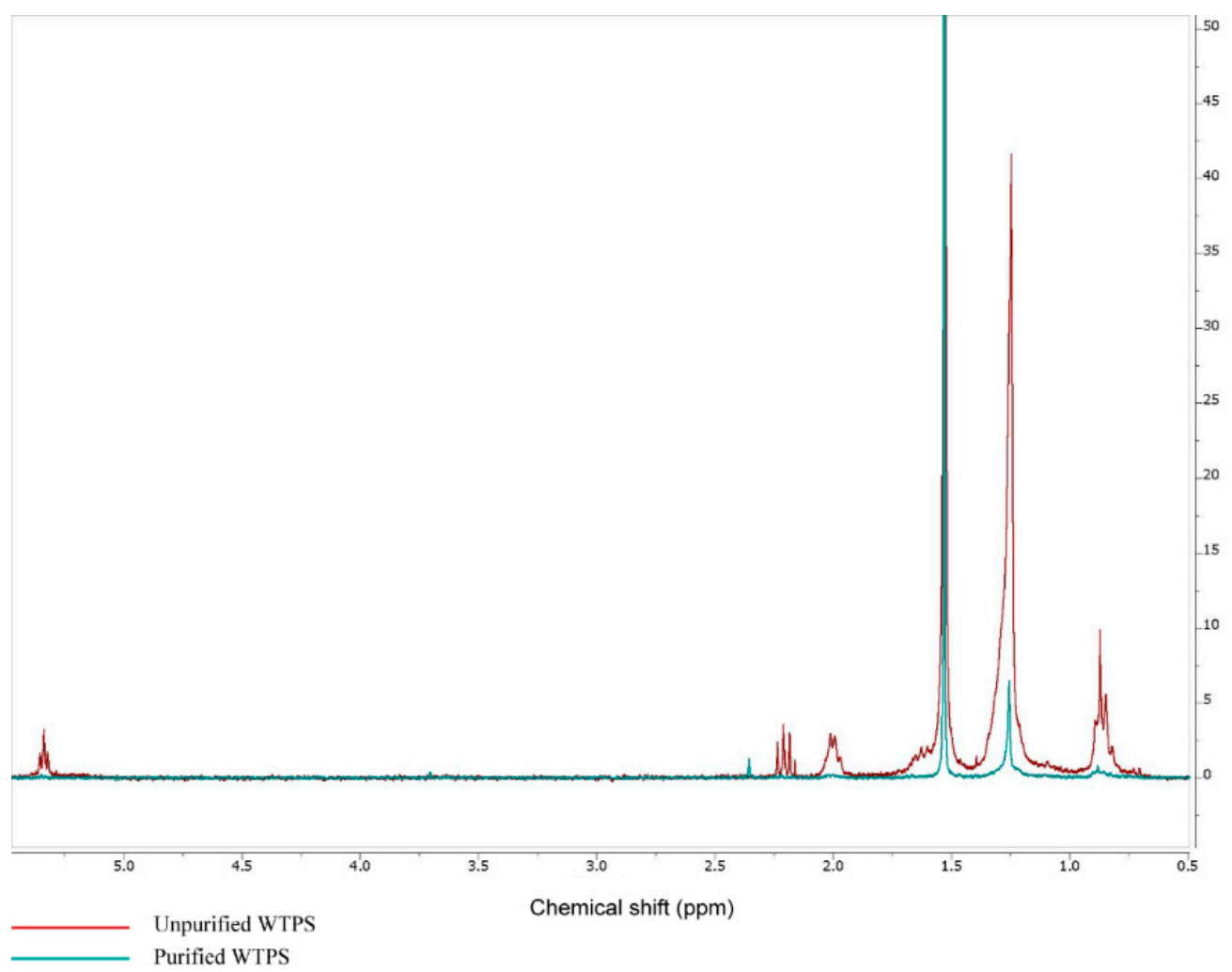

Figure $4 .{ }^{1} \mathrm{H}-\mathrm{NMR}$ spectra of unpurified and purified WTPS. 
In general, the quantitative estimate of PHA could be determined by the intensity ratio of the signals, and as before, the unpurified sample had higher peaks compared to the unpurified WTPS, especially in the detection of PHA groups. This could be due to the purification process and the reduction of the amount of PHA in the purified sample.

\subsection{Determination of Optimal Viscosity and Electrospinning Parameters}

The optimal viscosity for the WTPS suspension was experimentally determined to be $20,000 \mathrm{mPas}$ ( $\pm 500 \mathrm{mPas}$ ). This viscosity provided satisfactory nanofiber morphology without visible defects, beads or droplets within the fiber structure (Figure 5 with marked arrows). Purified WTPS with lower viscosities did not lead to uniform structure of the electrospun material. During the electrospinning process of such suspensions, undesirable electrospraying effects occurred in the form of tiny droplets. Higher viscosities (above 20,000 mPas), on the other hand, clogged the electrospinning device system and thus disrupted the production process.

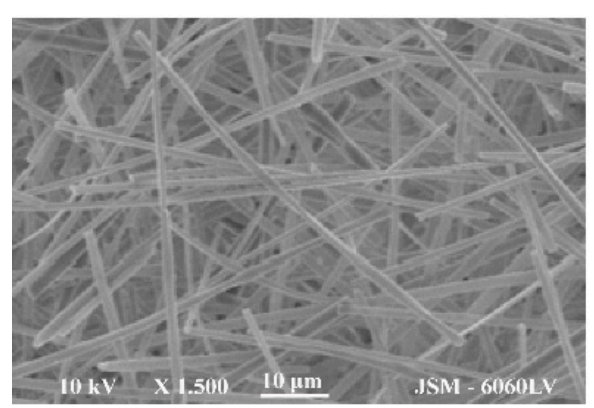

a)

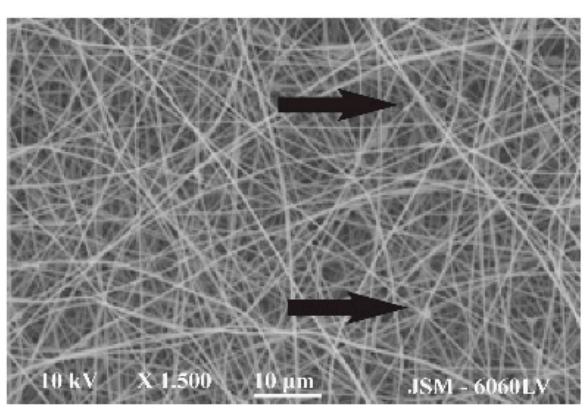

b)

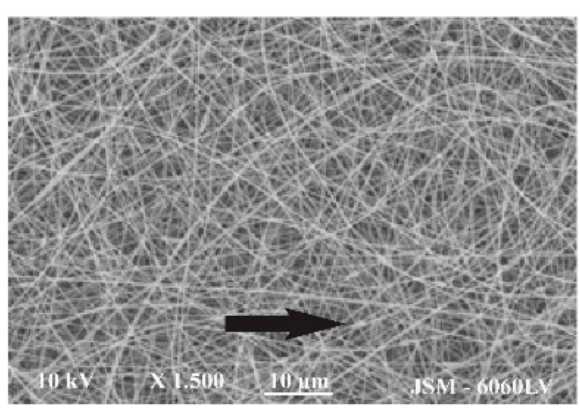

c)

Figure 5. SEM micrographs of final material (a) optimal-electrospun from suspension with a viscosity of 20,000 mPas; (b) electrospun from suspension with a viscosity of $5000 \mathrm{mPas}$; (c) electrospun from suspension with a viscosity of $2000 \mathrm{mPas}$ at $1500 \times$ magnification.

As described previously, the optimal parameters of the electrospinning process were a voltage of $19 \mathrm{kV}$, a flow rate of $200 \mu \mathrm{L} / \mathrm{h}$ and a distance of $15 \mathrm{~cm}$ between needle and collector. Only the sample prepared from a suspension with optimal viscosity was further analyzed. Based on the results of the preliminary tests, it shows better performance compared to the other two (sample b and c).

\subsection{Differential Scanning Calorimetry Characterization of the Final Material}

The DSC heating curve is shown in Figure 6. The analysis was done in one heating cycle only, since the nanofiber morphology of the material is disrupted by the heating and further cooling, reheating serves no purpose. A small peak on the derivative curve at $62.60{ }^{\circ} \mathrm{C}$ indicates the glass transition temperature of the new material. PHAs usually have a bit lower glass transition temperature, but since this material contains a considerable number of impurities, the increase might be a consequence. Low-intensity peaks around 130 and $137^{\circ} \mathrm{C}$ might also indicate the presence of impurities in the final material. The melting point of the material was detected at around $150{ }^{\circ} \mathrm{C}$, which is in accordance with the research published by Lorini et al. [36]. 
DSC

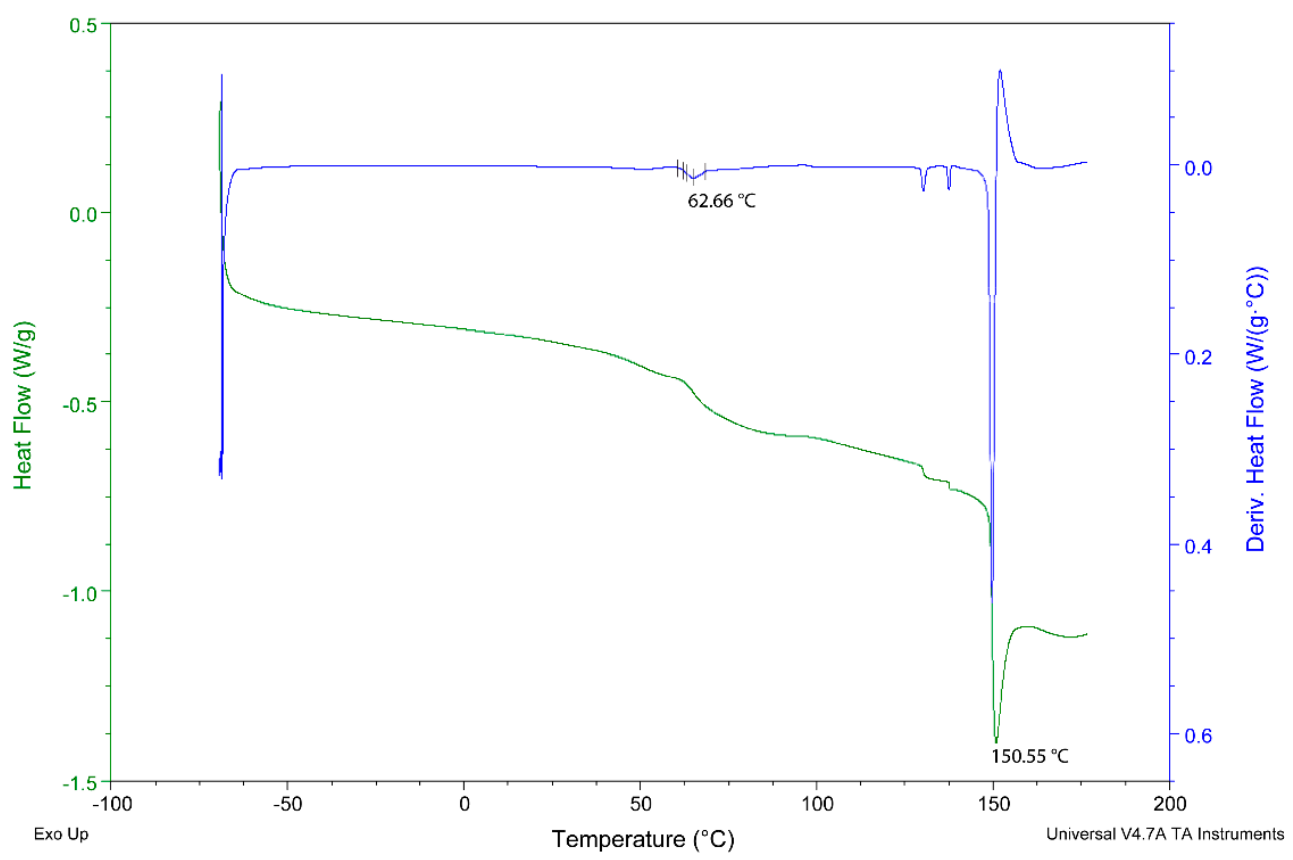

Figure 6. DSC of purified WTPS.

\subsection{Tensile Properties and Contact Angle Analysis of Final Material}

The results of the tensile analysis and contact angle analysis of the final material are summarized in Table 1 and presented in Figure 7. As can be seen from the results, the sample exhibited lower stress and strain than the results obtained in the literature [24-26]. The results confirmed a brittle sample, as only $0.422 \mathrm{~N} / \mathrm{mm}^{2}$ was applied to break it. The same trend was observed for strain, which was only $2.07 \%$. This was more than $50 \%$ lower compared to the literature results. The tensile tests confirmed that purified WTPS was suitable for performing electrospun material, but it was very brittle. Therefore, one of the solutions could be a combination with other waste biopolymers or recycled polymers to obtain flexible material in further research.

Table 1. Stress-strain with standard deviation and contact angle measurements for final material.

\begin{tabular}{ccc}
\hline Analysis Parameters & Sample & $\begin{array}{c}\text { Results from the Literature: } \\
\text { Bio-Based Electrospun Materials [37-39] }\end{array}$ \\
\hline Stress $\left(\mathrm{N} / \mathrm{mm}^{2}\right)$ & $0.422 \pm 0.053$ & $1.5-1.85$ \\
Strain $(\%)$ & $2.07 \pm 0.129$ & $4.71-13.8$ \\
Contact angle & $0^{\circ}$ & $0.4^{\circ}-22^{\circ}$ \\
\hline
\end{tabular}

As shown in Table 1, the newly produced material reached a meagre value of the contact angle determined with water at a time of $1 \mathrm{~s}\left(0^{\circ}\right)$. According to the solubility of the base material (WTPS) in the presence of EDTA in water, such a material property was expected. The presence of many accessible $\mathrm{OH}$ groups on the surface, in combination with other properties (size and interweaving of electrospun fibers), resulted in a material with high wettability. This property could prevent it from being used for packaging applications. However, with an appropriate blending method and/or surface treatment or coating, this could be drastically improved or adjusted. Since we wanted to present the properties of material derived only from WTPS in this study, these options were not used. Other chemicals that could improve this and possibly other properties of the material were also not used due to the preference for developing the new material in the most sustainable and environmentally friendly way possible. In the further development of the material, 
methods such as plasma and UV treatment and the possible use of other substances will also be used in accordance with these principles.

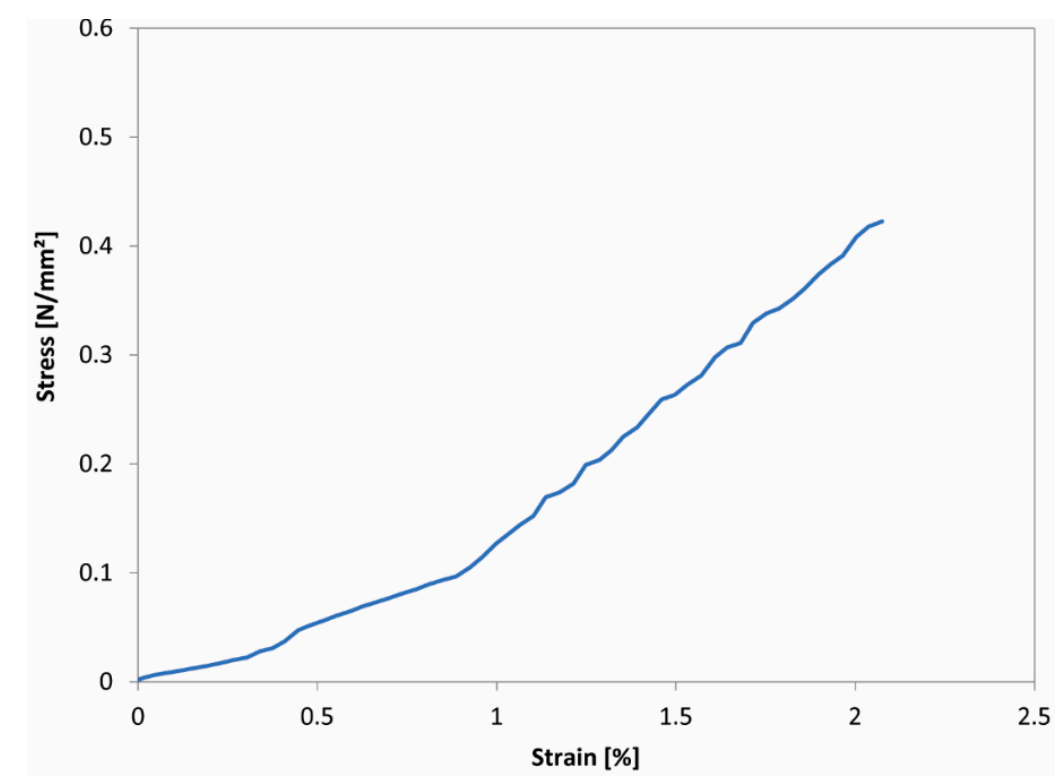

Figure 7. Stress-strain curve of the final material.

\section{Conclusions}

Biopolymers are currently in the spotlight in terms of their production and use, which is continuously increasing. This work evidences that it is possible to produce electrospun fibers from purified WTPS by using water and EDTA. Firstly, the viscosity was determined at 20,000 mPas, which led to satisfying nanofiber morphology, without visible defects, beads or drops within the fiber structure. Due to the presence of impurities in the WTPS, the glass transition temperature of the material was found to be at a higher temperature than usual for PHA, along with two low intensity peaks below the melting temperature. The melting point at $150{ }^{\circ} \mathrm{C}$ is within the range of temperatures characteristic for PHA polymers. The low amount of PHA was also confirmed in both samples. Due to the process of purification, the amount of PHA was lower in purified WTPS. However, all the analyzed properties showed that the final material was brittle and less stretchable compared to the packaging films on the market. Further research should be conducted on the possible addition of other biopolymers produced from alternatively sourced or recycled materials to purified WTPS to obtain a material with desired mechanical properties.

Author Contributions: Conceptualization, G.L. and U.V.-B.; methodology, G.L. and U.V.-B.; validation, G.L., A.M., B.P., S.N. and U.V.-B.; formal analysis, G.L., A.M. and U.V.-B.; investigation, G.L., A.M., D.M. and S.N.; writing_-original draft preparation, G.L., A.M., B.P., S.N., D.M. and U.V.-B.; writing-review and editing, G.L., A.M., D.M. and U.V.-B. All authors have read and agreed to the published version of the manuscript.

Funding: The first author C.L. MSc extends his gratitude to COST action FP1405-Active and Intelligent Fiber-Based Packaging for providing the grant to support the Short Term Scientific Mission (STSM) research activities at the University of Novi Sad, Faculty of Technology, Novi Sad, Serbia.

Institutional Review Board Statement: Not applicable.

Informed Consent Statement: Not applicable.

Data Availability Statement: Not applicable.

Conflicts of Interest: The authors declare no conflict of interest. 


\section{References}

1. Smithers Pira. Value Estimations \& Global Packaging Trends in 2018 and Beyond I Smithers Pira. Available online: https:/ /www. smitherspira.com/resources/2018/january/value-estimations-for-packaging-in-2018-and-beyond (accessed on 8 August 2020).

2. World Economic Forum. The New Plastics Economy Rethinking the Future of Plastics; World Economic Forum: Geneva, Switzerland, 2016; 14p.

3. Matthews, C.; Moran, F.; Jaiswal, A.K. A review on European Union's strategy for plastics in a circular economy and its impact on food safety. J. Clean. Prod. 2021, 283, 125263. [CrossRef]

4. Plastics Strategy. Available online: https://ec.europa.eu/environment/strategy/plastics-strategy_en (accessed on 24 April 2021).

5. Schettini, E.; Santagata, G.; Malinconico, M.; Immirzi, B.; Scarascia Mugnozza, G.; Vox, G. Recycled wastes of tomato and hemp fibres for biodegradable pots: Physico-chemical characterization and field performance. Resour. Conserv. Recycl. 2013, 70, 9-19. [CrossRef]

6. Manara, P.; Zabaniotou, A. Towards sewage sludge based biofuels via thermochemical conversion-A review. Renew. Sustain. Energy Rev. 2012, 16, 2566-2582. [CrossRef]

7. Suárez-Iglesias, O.; Collado, S.; Oulego, P.; Díaz, M. Graphene-family nanomaterials in wastewater treatment plants. Chem. Eng. J. 2017, 313, 121-135. [CrossRef]

8. Tyagi, V.; Lo, S. Sludge: A waste or renewable source for energy and resources recovery? Renew. Sustain. Energy Rev. 2013, 25, 708-728. [CrossRef]

9. Gherghel, A.; Teodosiu, C.; De Gisi, S. A review on wastewater sludge valorisation and its challenges in the context of circular economy. J. Clean. Prod. 2019, 228, 244-263. [CrossRef]

10. Väisänen, T.; Haapala, A.; Lappalainen, R.; Tomppo, L. Utilization of agricultural and forest industry waste and residues in natural fiber-polymer composites: A review. Waste Manag. 2016, 54, 62-73. [CrossRef]

11. Figueroa, G.A.; Homann, T.; Rawel, H.M. Coffee production wastes: Potentials and perspectives. Austin Food Sci $2016,1,1-5$.

12. Malara, A.; Paone, E.; Frontera, P.; Bonaccorsi, L.; Panzera, G.; Mauriello, F. Sustainable exploitation of coffee silverskin in water remediation. Sustainability 2018, 10, 3547. [CrossRef]

13. Weston, M.; Phan, M.A.T.; Arcot, J.; Chandrawati, R. Anthocyanin-based sensors derived from food waste as an active use-by date indicator for milk. Food Chem. 2020, 326, 127017. [CrossRef] [PubMed]

14. Mannu, A.; Garroni, S.; Ibanez Porras, J.; Mele, A. Available technologies and materials for waste cooking oil recycling. Processes 2020, 8, 366. [CrossRef]

15. Yaakob, Z.; Mohammad, M.; Alherbawi, M.; Alam, Z.; Sopian, K. Overview of the production of biodiesel from waste cooking oil. Renew. Sustain. Energy Rev. 2013, 18, 184-193. [CrossRef]

16. Singhabhandhu, A.; Tezuka, T. The waste-to-energy framework for integrated multi-waste utilization: Waste cooking oil, waste lubricating oil, and waste plastics. Energy 2010, 35, 2544-2551. [CrossRef]

17. Shirvanimoghaddam, K.; Motamed, B.; Ramakrishna, S.; Naebe, M. Death by waste: Fashion and textile circular economy case. Sci. Total Environ. 2020, 718, 137317. [CrossRef] [PubMed]

18. Dissanayake, D.G.K.; Weerasinghe, D.U.; Thebuwanage, L.M.; Bandara, U.A.A.N. An environmentally friendly sound insulation material from post-industrial textile waste and natural rubber. J. Build. Eng. 2021, 33, 101606. [CrossRef]

19. Girard, E.B.; Kaliwoda, M.; Schmahl, W.W.; Wörheide, G.; Orsi, W.D. Biodegradation of textile waste by marine bacterial communities enhanced by light. Environ. Microbiol. Rep. 2020, 12, 406-418. [CrossRef]

20. Kumar, V.; Pathak, P.; Bhardwaj, N.K. Waste paper: An underutilized but promising source for nanocellulose mining. Waste Manag. 2020, 102, 281-303. [CrossRef]

21. Zakarya, I.A.; Fazhil, N.S.A.; Izhar, T.N.T.; Zaaba, S.K.; Jamaluddin, M.N.F. Municipal Solid Waste Characterization and Quantification as A Measure Towards Effective Solid Waste Management in UniMAP. IOP Conf. Ser. Earth Environ. Sci. 2020, 616, 12047. [CrossRef]

22. Zhang, Q.; Khan, M.U.; Lin, X.; Yi, W.; Lei, H. Green-composites produced from waste residue in pulp and paper industry: A sustainable way to manage industrial wastes. J. Clean. Prod. 2020, 262, 121251. [CrossRef]

23. Albuquerque, P.; Malafaia, C. Perspectives on the production, structural characteristics and potential applications of bioplastics derived from polyhydroxyalkanoates. Int. J. Biol. Macromol. 2018, 107, 615-625. [CrossRef]

24. Kumar, M.; Ghosh, P.; Khosla, K.; Thakur, I. Recovery of polyhydroxyalkanoates from municipal secondary wastewater sludge. Bioresour. Technol. 2018, 255, 111-115. [CrossRef]

25. Mannina, G.; Presti, D.; Montiel-Jarillo, G.; Suárez-Ojeda, M. Bioplastic recovery from wastewater: A new protocol for polyhydroxyalkanoates (PHA) extraction from mixed microbial cultures. Bioresour. Technol. 2018, 282, 361-369. [CrossRef]

26. Liu, H.; Gough, C.R.; Deng, Q.; Gu, Z.; Wang, F.; Hu, X. Recent advances in electrospun sustainable composites for biomedical, environmental, energy, and packaging applications. Int. J. Biol. Macromol. 2020, 21, 4019. [CrossRef]

27. Dodero, A.; Alloisio, M.; Vicini, S.; Castellano, M. Preparation of composite alginate-based electrospun membranes loaded with ZnO nanoparticles. Carbohydr. Polym. 2020, 227, 115371. [CrossRef] [PubMed]

28. de Souza, E.J.D.; Kringel, D.H.; Dias, A.R.G.; da Rosa Zavareze, E. Polysaccharides as wall material for the encapsulation of essential oils by electrospun technique. Carbohydr. Polym. 2021, 265, 118068. [CrossRef] [PubMed]

29. Fang, H.H.P.; Jia, X.S. Extraction of extracellular polymer from anaerobic sludges. Biotechnol. Tech. 1996, 10, 803-808. [CrossRef] 
30. Hsiao, M.H.; Lin, K.H.; Liu, D.M. Improved pH-responsive amphiphilic carboxymethyl-hexanoyl chitosan-poly (acrylic acid) macromolecules for biomedical applications. Soft Matter 2013, 9, 2458-2466. [CrossRef]

31. Sun, Y.; Zhang, F.; Wu, D.; Zhu, H. Roles of polyacrylate dispersant in the synthesis of well-dispersed $\mathrm{BaSO}_{4}$ nanoparticles by simple precipitation. Particuology 2014, 14, 33-37. [CrossRef]

32. Liu, S.; Gu, L.; Zhao, H.; Chen, J.; Yu, H. Corrosion resistance of graphene-reinforced waterborne epoxy coatings. J. Mater. Sci. Technol. 2016, 32, 425-431. [CrossRef]

33. Alves Filho, E.G.; Alexandre e Silva, L.M.; Ferreira, A.G. Advancements in waste water characterization through NMR spectroscopy. Magn. Reson. Chem. 2015, 53, 648-657. [CrossRef]

34. Tan, G.Y.A.; Chen, C.L.; Li, L.; Ge, L.; Wang, L.; Razaad, I.M.N.; Li, Y.; Mo, Y.; Wang, J.Y. Start a research on biopolymer polyhydroxyalkanoate (PHA): A review. Polymers 2014, 6, 706-754. [CrossRef]

35. Nkrumah-Agyeefi, S.; Scholz, C. Chemical modification of functionalized polyhydroxyalkanoates via "Click" chemistry: A proof of concept. Int. J. Biol. Macromol. 2017, 95, 796-808. [CrossRef] [PubMed]

36. Lorini, L.; Martinelli, A.; Pavan, P.; Majone, M.; Valentino, F. Downstream processing and characterization of polyhydroxyalkanoates (PHAs) produced by mixed microbial culture (MMC) and organic urban waste as substrate. Biomass Convers. Biorefinery 2021, 11, 693-703. [CrossRef]

37. de Oliveira Santos, R.P.; Ramos, L.A.; Frollini, E. Bio-based electrospun mats composed of aligned and nonaligned fibers from cellulose nanocrystals, castor oil, and recycled PET. Int. J. Biol. Macromol. 2020, 163, 878-887. [CrossRef] [PubMed]

38. Rossi, F.; Ramos, L.A.; Frollini, E. Renewable resources and a recycled polymer as raw materials: Mats from electrospinning of lignocellulosic biomass and PET solutions. Polymers 2018, 10, 538.

39. Santos, R.P.; Rodrigues, B.V.; Ramires, E.C.; Ruvolo-Filho, A.C.; Frollini, E. Bio-based materials from the electrospinning of lignocellulosic sisal fibers and recycled PET. Ind. Crops Prod. 2015, 72, 69-76. [CrossRef] 